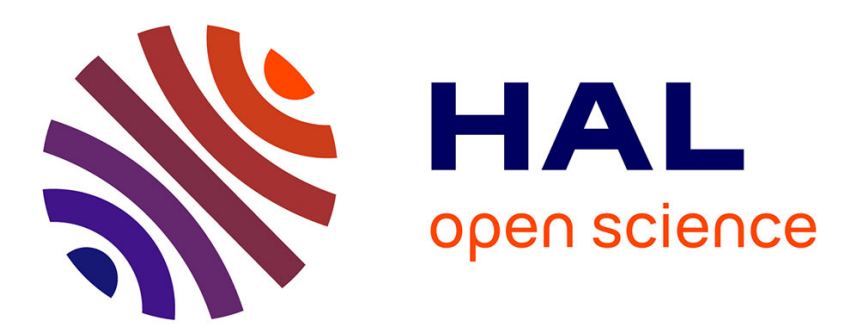

\title{
Texture development in Fe-doped alumina ceramics via templated grain growth and their application to carbon nanotube growth
}

Yasemin Çelik, Ender Suvaci, Alicia Weibel, Alain Peigney, Emmanuel Flahaut

\section{To cite this version:}

Yasemin Çelik, Ender Suvaci, Alicia Weibel, Alain Peigney, Emmanuel Flahaut. Texture development in Fe-doped alumina ceramics via templated grain growth and their application to carbon nanotube growth. Journal of the European Ceramic Society, 2013, vol. 33, pp. 1093-1100. 10.1016/j.jeurceramsoc.2012.11.013 . hal-00857498

\section{HAL Id: hal-00857498 https://hal.science/hal-00857498}

Submitted on 3 Sep 2013

HAL is a multi-disciplinary open access archive for the deposit and dissemination of scientific research documents, whether they are published or not. The documents may come from teaching and research institutions in France or abroad, or from public or private research centers.
L'archive ouverte pluridisciplinaire HAL, est destinée au dépôt et à la diffusion de documents scientifiques de niveau recherche, publiés ou non, émanant des établissements d'enseignement et de recherche français ou étrangers, des laboratoires publics ou privés. 


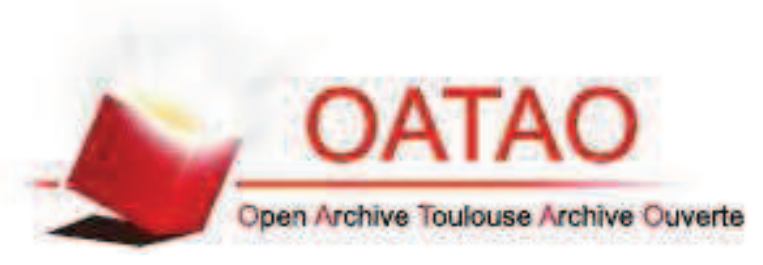

\section{Open Archive Toulouse Archive Ouverte (OATAO)}

OATAO is an open access repository that collects the work of Toulouse researchers and makes it freely available over the web where possible.

This is an author-deposited version published in: http://oatao.univ-toulouse.fr/ Eprints ID: 8788

To link to this article: DOI: $10.1016 / \mathrm{j}$.jeurceramsoc.2012.11.013 URL: http://dx.doi.org/10.1016/j.jeurceramsoc.2012.11.013

To cite this version: Çelik, Yasemin and Suvac1, Ender and Weibel, Alicia and Peigney, Alain and Flahaut, Emmanuel Texture development in $\mathrm{Fe}$ doped alumina ceramics via templated grain growth and their application to carbon nanotube growth. (2013) Journal of the European Ceramic Society, vol. 33 (n 6). pp. 1093-1100. ISSN 0955-2219 


\title{
Texture development in Fe-doped alumina ceramics via templated grain growth and their application to carbon nanotube growth
}

\author{
Yasemin Çelik $^{\mathrm{a}}$, Ender Suvac1 ${ }^{\mathrm{a}, *}$, Alicia Weibel ${ }^{\mathrm{b}}$, Alain Peigney ${ }^{\mathrm{b}}$, Emmanuel Flahaut $^{\mathrm{b}, \mathrm{c}}$ \\ ${ }^{a}$ Department of Materials Science and Engineering, Anadolu University, 26480 Eskisehir, Turkey \\ ${ }^{\mathrm{b}}$ Université de Toulouse, UPS, INP, Institut Carnot Cirimat, 118 Route de Narbonne, F-31062 Toulouse cedex 9 France \\ ${ }^{\mathrm{c}}$ CNRS, Institut Carnot Cirimat, F-31062 Toulouse, France
}

\begin{abstract}
Fe-doped alumina $\left(\mathrm{Fe}-\mathrm{Al}_{2} \mathrm{O}_{3}\right)$ materials with a controlled microstructure could be designed for some special uses such as a substrate for carbon nanotube growth. In this study, Fe-doped $\mathrm{Al}_{2} \mathrm{O}_{3}$ ceramics with varying degrees of texture were prepared via Templated Grain Growth method and utilized for carbon nanotube synthesis by Catalytic Chemical Vapor Deposition in order to investigate how $\alpha-\mathrm{Al}_{2} \mathrm{O}_{3}$ crystal orientation affects carbon nanotube growth in polycrystalline ceramics. The degree of texture increased with the Fe content in the presence of liquid phase. Three kinds of carbon filaments (few-wall carbon nanotubes bundles, individual multi-wall nanotubes and carbon nanofibres) were observed over $\mathrm{Fe}^{-d o p e d ~} \mathrm{Al}_{2} \mathrm{O}_{3}$ ceramics with varying degrees of texture depending on the surface roughness, crystallographic orientation and the size of the catalyst nanoparticles. While well-textured substrates with a rough surface led to a small amount of randomly oriented carbon nanotube bundles, perpendicularly oriented individual multi-wall nanotubes were obtained over relatively smooth single crystal $\alpha-\mathrm{Al}_{2} \mathrm{O}_{3}$ platelet surfaces (basal planes) which remained in the matrix without growing.
\end{abstract}

Keywords: Fe-doped $\mathrm{Al}_{2} \mathrm{O}_{3}$; Tape casting; Templated grain growth; Carbon nanotubes

\section{Introduction}

Fe-doped alumina $\left(\mathrm{Fe}-\mathrm{Al}_{2} \mathrm{O}_{3}\right)$ ceramics exhibit potential as readily available and relatively low cost catalysts for carbon nanotubes (CNTs) synthesis. Peigney et al. ${ }^{1}$ have developed a catalytic route for the in situ formation of CNTs over a Fe$\mathrm{Al}_{2} \mathrm{O}_{3}$ powder by selective reduction of an alumina-hematite solid solution powder in $\mathrm{H}_{2}-\mathrm{CH}_{4}$ atmosphere. This simple and scalable technique provides a very homogeneous distribution of CNTs in the CNTs-Fe- $\mathrm{Al}_{2} \mathrm{O}_{3}$ nanocomposite powder, while avoiding the potentially hazardous effect of handling free CNTs in case of simple mixing with the matrix. Suvaci et al. ${ }^{2,3}$ reported successful synthesis of CNTs over polycrystalline Fe-doped $\mathrm{Al}_{2} \mathrm{O}_{3}$ ceramics by catalytic chemical vapor deposition (CCVD). The authors reported that the size and density of the catalytic nanoparticles showed variations depending

\footnotetext{
* Corresponding author. Tel.: +90 222321 3550/6359; fax: +90 2223239501. E-mail address: esuvaci@anadolu.edu.tr (E. Suvac1).
}

on the surface characteristics ${ }^{2,3}$; however, they did not give information about the surface density of these nanoparticles on the polycrystalline surface and did not evaluate whether there is any relationship between crystallographic orientation of grains and CNTs growth. Hongo et al. ${ }^{4}$ reported that the single-wall CNTs (SWNTs) yield depends on the crystallographic orientation of sapphire substrate coated with Fe-film and on the film thickness. It is obvious from these studies that there is a correlation between the crystallographic orientation of the single crystal substrate and CNTs growth. Although several single crystals such as quartz and sapphire with a specific crystallographic orientation have been investigated as a substrate for CNTs synthesis, ${ }^{4-7}$ polycrystalline ceramics with a textured microstructure have not been used in CNTs growth studies to the best of our knowledge. By texturing Fe-doped $\mathrm{Al}_{2} \mathrm{O}_{3}$ ceramics, one can evaluate effect of orientation on CNTs growth and hence benefit from the orientation of certain crystallographic planes on the substrate surface for CNTs growth. The crystals of a polycrystalline material can be oriented at certain planes by a variety of techniques such as hot pressing and sinter forging of 
systems containing oriented whisker-, fibre-, or platelet-shaped particles. ${ }^{8-10}$ Templated Grain Growth (TGG) is another widely utilized method for the production of textured ceramics. ${ }^{11}$ In TGG, a small number of large anisometric template particles are aligned in a fine powder matrix during tape casting, slip casting, extrusion or uniaxial pressing. After densification, these larger anisometric grains grow and consume the matrix grains to yield ceramics with textured grains and high degrees of crystallographic orientation. Consequently, the objective of this study was to investigate how to tailor microstructure in Fe-doped $\mathrm{Al}_{2} \mathrm{O}_{3}$ ceramics via TGG method in order to achieve a controlled degree of texture by controlling the amount of Fe and/or sintering conditions, and then to investigate the possible use of these ceramics as substrates for the catalytic growth of CNTs. It was also aimed to evaluate role of crystallographic orientation of $\mathrm{Fe}$-doped $\alpha-\mathrm{Al}_{2} \mathrm{O}_{3}$ crystals on CNTs growth.

\section{Experimental procedure}

\subsection{Texture formation}

$1 \%, 2 \%, 5 \%$ and 10 cat. $\%$ Fe-doped $\mathrm{Al}_{2} \mathrm{O}_{3}$ powders $\left(\mathrm{Al}_{2(1-x)} \mathrm{Fe}_{2 x} \mathrm{O}_{3}(x \leq 0.1)\right)$, later used as matrix material for textured substrate fabrication, were synthesized by combustion synthesis method as described by Cordier et al. ${ }^{12}$ In this process, the required proportion of aluminum nitrate nonahydrate $\left(\mathrm{Al}\left(\mathrm{NO}_{3}\right)_{3} \cdot 9 \mathrm{H}_{2} \mathrm{O}\right.$, Merck, extra pure) and iron nitrate nonahydrate $\left(\mathrm{Fe}\left(\mathrm{NO}_{3}\right)_{3} \cdot 9 \mathrm{H}_{2} \mathrm{O}\right.$, Merck, GR for analysis) were dissolved in distilled water in a Pyrex ${ }^{\circledR}$ beaker. A mixture of citric acid and urea (75\% citric acid and $25 \%$ urea) was used as fuel, in a quantity equal to twice the stoichiometric ratio. ${ }^{12}$ The required amount of citric acid and urea were dissolved in distilled water and then added into the nitrate solution. The solution was stirred at $600 \mathrm{rpm}$ and ca. $120^{\circ} \mathrm{C}$ for $1 \mathrm{~h}$. The Pyrex ${ }^{\circledR}$ beaker was then placed in a preheated furnace, at $550^{\circ} \mathrm{C}$, and kept there for at least $20 \mathrm{~min}$. The as-synthesized amorphous powder was subjected to two-stage calcination process: it was first heated at $5^{\circ} \mathrm{C} / \mathrm{min}$ up to $600^{\circ} \mathrm{C}, 1.5 \mathrm{~h}$ of dwell time in order to remove the residual carbon and then at $15^{\circ} \mathrm{C} / \mathrm{min}$ up to $1100^{\circ} \mathrm{C}, 20 \mathrm{~min}$ of dwell time to obtain the $\alpha$-phase. After calcination, the powders were attrition milled at $250 \mathrm{rpm}$ for $4 \mathrm{~h}$ in distilled water by using yttria-stabilized $\mathrm{ZrO}_{2}$ balls, $3 \mathrm{~mm}$ in diameter.

Fe-doped $\mathrm{Al}_{2} \mathrm{O}_{3}$ ceramic substrates were prepared by tape casting. The matrix consisted of the $\alpha-\mathrm{Al}_{2(1-x)} \mathrm{Fe}_{2 x} \mathrm{O}_{3}$ powder with a specific surface area of $\sim 33 \mathrm{~m}^{2} / \mathrm{g}$. $5 \mathrm{vol} \% \alpha-$ $\mathrm{Al}_{2} \mathrm{O}_{3}$ platelets (Pyrofine Platelets, Elf-Atochem, Pierre-Benite, France) of $20 \pm 5 \mu \mathrm{m}$ in diameter and $2.0 \mu \mathrm{m}$ thickness were added to the matrix as templates. $\mathrm{CaO}$ and $\mathrm{SiO}_{2}$ were used as high temperature glass formers at a ratio of 1.3:1 in an amount of 0,1 or 5 vol\% of the matrix powder. Tape casting slurry consisted of an azeotropic mixture of methylethylketone (MEK, 66 vol\%) and ethanol (EtOH, 34 vol\%) as solvent, sodiumtripolyphosphate (STPP) as dispersant, polyvinylbutyral (PVB Butvar 76) as binder, and polyethylene glycol (PEG 3000, Fluka, Steinheim, Switzerland) and dibutylphthalate (DBP) as plasticizers.

A suspension with 39 vol\% solids loading was prepared by dispersing $\alpha-\mathrm{Al}_{2(1-x)} \mathrm{Fe}_{2 x} \mathrm{O}_{3}$ powder in the azeotropic mixture of MEK and EtOH with 8 vol\% STPP by ball milling for $4 \mathrm{~h}$ using yittria-stabilized $\mathrm{ZrO}_{2}$ balls, $3 \mathrm{~mm}$ in diameter. PEG (11 vol\%) and DBP ( 4 vol\%) were added to the suspension and again ball milled for $2 \mathrm{~h}$. Then, PVB (23 vol\%) was added and the suspension was again ball milled for additional $15 \mathrm{~h}$. After ball milling, $\alpha-\mathrm{Al}_{2} \mathrm{O}_{3}$ platelets were added to the slurry and mixed with a magnetic stirrer for $2 \mathrm{~h}$. The prepared slurry was tape casted on a glass plate at a blade height of $400 \mu \mathrm{m}$ at a $30 \mathrm{~cm} / \mathrm{s}$ casting speed. After drying at ambient conditions for $30 \mathrm{~min}$, the tape was cut and laminated at $45 \mathrm{MPa}$ and $70^{\circ} \mathrm{C}$ for $10 \mathrm{~min}$. Laminated tapes were heat treated for removing organics by heating the samples to $450{ }^{\circ} \mathrm{C}$ at a rate of $1{ }^{\circ} \mathrm{C} / \mathrm{min}$ and holding them at this temperature for $2 \mathrm{~h}$. Unless otherwise noted, the samples were sintered at $1600^{\circ} \mathrm{C}$ for $2 \mathrm{~h}$ in air with heating and cooling rates of $10^{\circ} \mathrm{C} / \mathrm{min}$. The notation for samples is $x$ FeyLP, where $x$ is the cationic percent of $\mathrm{Fe}$ in the $\alpha-\mathrm{Al}_{2(1-x)} \mathrm{Fe}_{2 x} \mathrm{O}_{3}$ powder and $\mathrm{y}$ is the volume fraction of liquid phase formers (LP), $\mathrm{CaO}+\mathrm{SiO}_{2}$, in the initial powder mixture. The volume fraction of $\alpha-\mathrm{Al}_{2} \mathrm{O}_{3}$ platelets (i.e., PL) was 5 vol\% for all samples unless otherwise indicated.

Microstructure development of sintered samples was examined using scanning electron microscope (SEM, Zeiss EVO 50). The SEM analyses were performed on polished and thermally etched cross-section surfaces. The dimensions and aspect ratios of anisotropic grains were directly measured from micrographs (at least 24 measurements) and averaged. Crystallographic texture development in the samples was characterized by an X-ray diffractometer (XRD, Rigaku Rint 2200, Tokyo, Japan) with $\mathrm{CuK} \alpha_{1}$ radiation. Texture fraction of the samples was determined by Lotgering Factor, which is an X-ray based semiquantitative characterization method. ${ }^{13}$

\subsection{Carbon nanotube growth}

The sintered samples were then placed in alumina boats in the middle of a CCVD chamber and reduced in $\mathrm{H}_{2}-\mathrm{CH}_{4}$ gas mixture $\left(82 \mathrm{~mol} \% \mathrm{H}_{2}\right.$ as reducing gas and $18 \mathrm{~mol}_{0} \mathrm{CH}_{4}$ as carbon source) at $1000{ }^{\circ} \mathrm{C}$ with a heating and cooling rate of $5 \% \mathrm{~min}$. No dwell time was applied. ${ }^{1,14}$ After CCVD, the samples were characterized by field-emission-gun scanning electron microscope (FEG-SEM, Jeol JSM 6700F at TEMSCAN, Universite Paul-Sabatier).

\section{Results and discussion}

\subsection{Texture development}

Texture development was investigated as a function of $\mathrm{Fe}$ content and liquid phase former amount by keeping $\alpha-\mathrm{Al}_{2} \mathrm{O}_{3}$ template amount, sintering temperature and time constant. The SEM micrographs in Fig. 1 show the effect of Fe-content on the microstructure development of $5 \mathrm{vol} \%$ template $\left(\alpha-\mathrm{Al}_{2} \mathrm{O}_{3}\right)$ containing alumina samples solid-state sintered at $1600{ }^{\circ} \mathrm{C}$ for $2 \mathrm{~h}$. No texture could be achieved for the solid-state sintered $\mathrm{Fe}$-doped $\mathrm{Al}_{2} \mathrm{O}_{3}$ samples at that temperature, whatever their $\mathrm{Fe}$ content. Neither matrix nor platelet grains exhibited significant grain growth in the samples with low Fe content (i.e., 1Fe0LP 

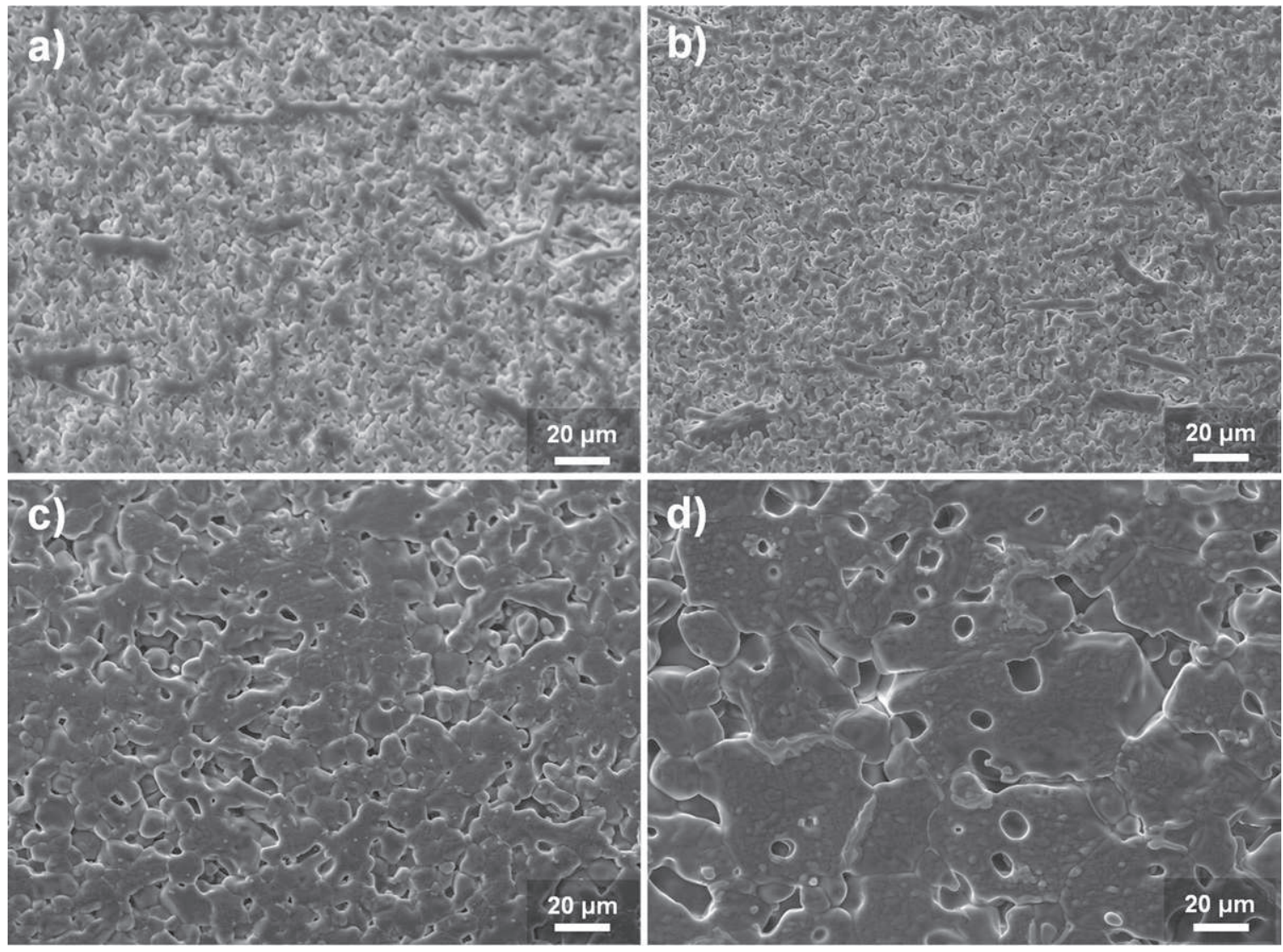

Fig. 1. SEM micrographs of (a) $1 \mathrm{Fe} 0 \mathrm{LP}$, (b) $2 \mathrm{Fe} 0 \mathrm{LP}$, (c) $5 \mathrm{Fe} 0 \mathrm{LP}$ and (d) $10 \mathrm{Fe} 0 \mathrm{LP}$ samples sintered $1600^{\circ} \mathrm{C}$ for $2 \mathrm{~h}$.

and $2 \mathrm{Fe} 0 \mathrm{LP}$ ) due to limited degree of densification, although the samples were sintered at a relatively high temperature (Fig. 1(a) and (b)). This retardation in densification could be attributed to the negative effect of platelets on the packing of the matrix particles. Özer et al. ${ }^{15}$ and Belmonte et al. ${ }^{16}$ investigated the sintering behavior of alumina powder compacts containing alumina platelet particles and showed that $\alpha-\mathrm{Al}_{2} \mathrm{O}_{3}$ platelet particles hindered densification. Carisey et al. ${ }^{17}$ also suggested that platelets constrained densification in solid-state sintered $\mathrm{Al}_{2} \mathrm{O}_{3}$. While 1 and 2 cat. $\%$ Fe-doping could not suppress the negative effect of platelets on densification, it was observed that increasing the $\mathrm{Fe}$ content to 5 and especially to 10 cat.\% influenced the microstructure development of platelet-containing alumina significantly (Fig. 1(c) and (d)). In 5Fe0LP sample, matrix grains also grew to some extent besides the platelets, leading to large pores in the microstructure (Fig. 1(c)). Increasing the Fe content further to 10 cat.\% (10Fe0LP) resulted in exaggerated grain growth, where it is not easy to distinguish whether these abnormally and isotropically grown grains formed from the matrix or from the platelets (Fig. 1(d)). Both inside and between these grains, a high amount of large pores were formed. It is obvious from the micrographs that certain amount of Fe-doping (i.e., $\geq 5$ cat.\%) improves the sintering behavior of platelet-containing $\mathrm{Al}_{2} \mathrm{O}_{3}$. Calculations based on sintering equations showed that the diffusion coefficients increase with increasing $\mathrm{Fe}$ content; consequently, the sintering rate of $\mathrm{Fe}$-doped $\mathrm{Al}_{2} \mathrm{O}_{3}$ increases with increasing total $\mathrm{Fe}$ amount. ${ }^{18}$ It was also reported that addition of $\mathrm{Fe}_{2} \mathrm{O}_{3}$ into $\mathrm{Al}_{2} \mathrm{O}_{3}$ over a certain amount can promote anisotropic and exaggerated grain growth at high temperatures such as $1650{ }^{\circ} \mathrm{C} .{ }^{19}$ This arises from reduction of some of the $\mathrm{Fe}^{3+}$ to $\mathrm{Fe}^{2+}$ leading to creation of oxygen vacancies or aluminum interstitials which increase grain boundary diffusion and from segregation of a significant amount of $\mathrm{Fe}^{2+}$ to grain boundaries resulting in an exaggerated grain growth. ${ }^{19}$ At $1450-1500{ }^{\circ} \mathrm{C}$ in air, iron is primarily in the trivalent state, and only $2 \%$ of the total $\mathrm{Fe}^{3+}$ is reduced. ${ }^{20}$ The solubility of $\mathrm{Fe}^{2+}$ in $\mathrm{Al}_{2} \mathrm{O}_{3}$ is $0.7-1.9 \%$ at $1450{ }^{\circ} \mathrm{C} .{ }^{19,21}$ The reduction of $\mathrm{Fe}^{3+}$ to $\mathrm{Fe}^{2+}$ over the solubility limit results in segregation of free iron oxide at grain boundaries forming $\mathrm{Fe}_{2} \mathrm{O}_{4}$ phase and causes rapid growth and uncontrolled microstructural development. ${ }^{19,22}$ In the present study, the increasing grain growth with increasing $\mathrm{Fe}^{3+}$ doping could be attributed to formation of higher amount of $\mathrm{Fe}^{2+}$ due to reduction of $\mathrm{Fe}^{3+}$ cations. For the samples with lower iron content (e.g., 1 and 2 cat.\%), the amount of reduced $\mathrm{Fe}^{3+}$ may not be sufficient to promote enhanced grain growth. For the $5 \mathrm{Fe} 0 \mathrm{LP}$ sample, the amount of $\mathrm{Fe}^{2+}$ formed by the reduction of $\mathrm{Fe}^{3+}$ is higher than that of the $1 \mathrm{Fe} 0 \mathrm{LP}$ and $2 \mathrm{Fe} 0 \mathrm{LP}$; however the amount of $\mathrm{Fe}^{2+}$ is still below the solubility limit; therefore, the enhanced grain growth could be explained by the mechanism based on the creation of oxygen vacancies as suggested by Tartaj and Messing. ${ }^{19}$ As the iron content increases to 10 cat. \%, higher amount of $\mathrm{Fe}^{3+}$ is reduced (over the solubility limit) and this may cause the segregation at grain boundaries resulting to an exaggerated grain growth. However, a textured 

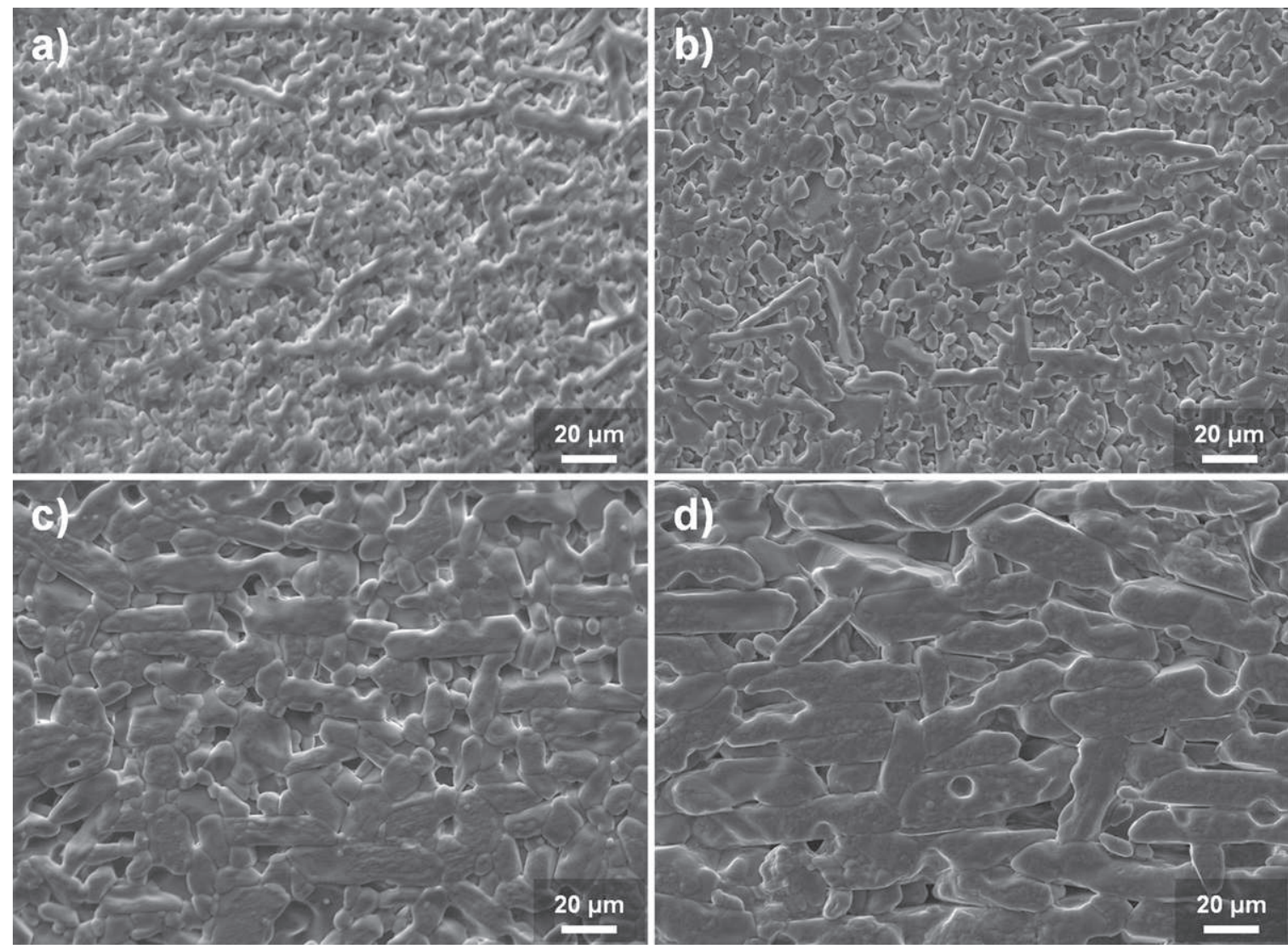

Fig. 2. SEM micrographs of (a) 1Fe1LP, (b) 2Fe1LP, (c) 5Fe1LP and (d) $10 \mathrm{Fe} 1 \mathrm{LP}$ samples sintered at $1600^{\circ} \mathrm{C}$ for $2 \mathrm{~h}$.

microstructure could not be achieved for the solid state sintered Fe-doped $\mathrm{Al}_{2} \mathrm{O}_{3}$ samples due to uncontrolled microstructure development, although the negative effect of platelet particles on densification of $\mathrm{Al}_{2} \mathrm{O}_{3}$ was suppressed by certain amount of Fe-doping.

Therefore, the samples were also liquid-phase sintered with different liquid phase amounts to be able to control the microstructure, based on the information from the previous studies where it was shown that liquid phase sintering reduces constrained densification caused by the template particles and accelerates grain growth ${ }^{23-25}$ and where it was reported that the addition of $\mathrm{CaO}$ and $\mathrm{SiO}_{2}$ creates favorable kinetic conditions for anisotropic grain growth during sintering. ${ }^{24,26}$

Fig. 2(a)-(d) show the SEM micrographs of liquid phased sintered 1Fe1LP, 2Fe1LP, 5Fe1LP and 10Fe1LP samples, respectively. The liquid phase regulated the microstructure and promoted anisotropic growth of the platelets in the Fe-doped $\mathrm{Al}_{2} \mathrm{O}_{3}$ samples, prominently as from 5 cat.\% Fe doping. The degree of texture increased with increasing Fe content at the presence of liquid phase, due to existence of the strong influence of certain amount of Fe-doping on the sintering kinetics of alumina and the effect of liquid phase on anisotropic growth of the template particles together in the system. The texture formation becomes apparent with the 5\% Fe doping (Fig. 2(c)) and the 10Fe1LP system shows the highest morphological texture among the other 1\% LP former containing samples (Fig. 2(d)). The average aspect ratio of the anisotropic grains in this sample is $\sim 4.1$ with an average diameter of $59 \mu \mathrm{m}$ and thickness of
$14 \mu \mathrm{m}$. Besides the well oriented template grains along the tape casting direction, some misoriented templates are also present leading to the formation of large pores in the microstructure.

Fig. 3 shows the effect of 5\% LP former addition on the texture development of 5 and $10 \%$ Fe-doped samples, which were also sintered at $1600^{\circ} \mathrm{C}$ for $2 \mathrm{~h}$. The increased liquid phase amount led to more faceted template grains with a higher average aspect ratio in these samples. ${ }^{26}$ The aspect ratio of $10 \mathrm{Fe} 5 \mathrm{LP}$ sample was $\sim 6.1$. The average diameter of anisotropic grains in this sample was $57 \mu \mathrm{m}$ and the average thickness was $9 \mu \mathrm{m}$. Besides the aligned grains in the tape casting direction, some coarse matrix grains and misaligned anisotropic grains also remained. These grains hindered densification and subsequently the radial growth of aligned templates. Consequently, large pores between the template grains were formed, preventing to achieve a higher degree of texture. Seabaugh et al. ${ }^{26}$ reported that liquid phase dramatically affects densification and the faceting of grains and degree of grain faceting increases as the amount of liquid phase increases.

The XRD analyses of the top surfaces of 10Fe0LP, 10Fe1LP and 10Fe5LP samples are shown in Fig. 4. The XRD patterns revealed crystallographic texture in the liquid phase containing Fe-doped $\mathrm{Al}_{2} \mathrm{O}_{3}$ samples in agreement with the morphological texture, observed in SEM images. An increase in the ratio of

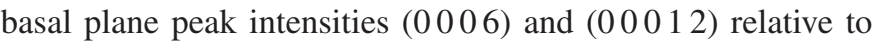
the peak with the highest intensity in the non-template containing sample $(11 \overline{2} 3)$ was observed. The intensity ratios of the

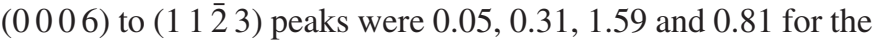



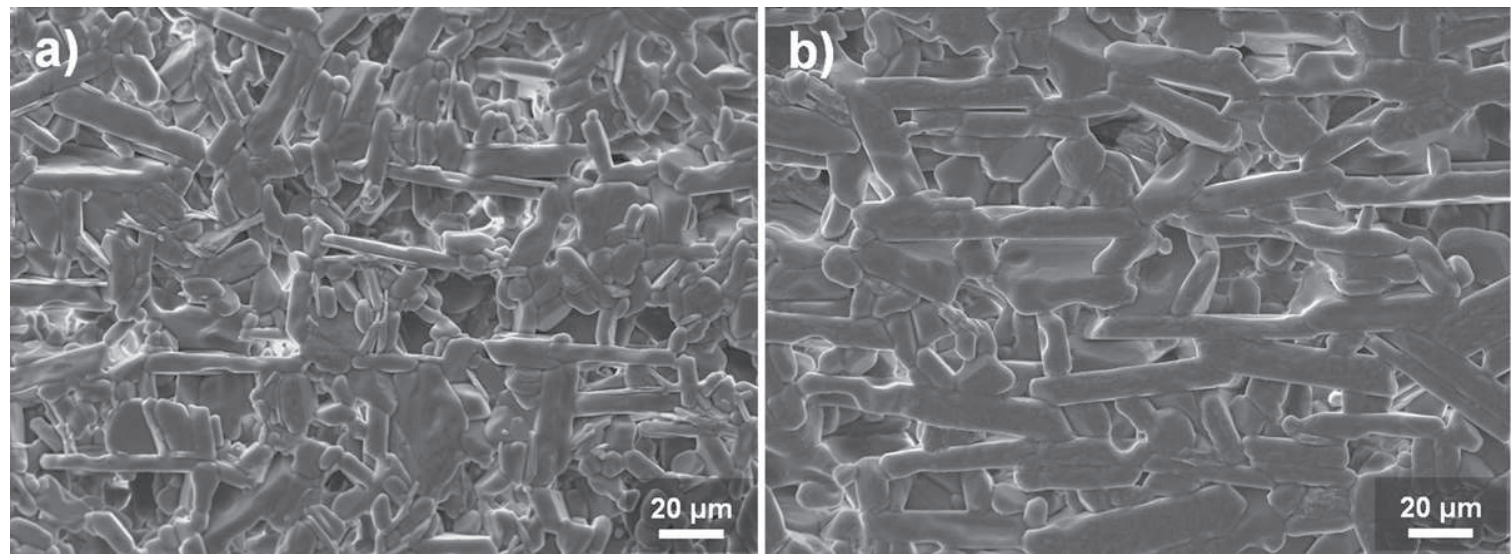

Fig. 3. SEM micrographs of (a) 5Fe5LP and (b) $10 \mathrm{Fe} 5 \mathrm{LP}$ samples sintered at $1600^{\circ} \mathrm{C}$ for $2 \mathrm{~h}$.

$10 \% \mathrm{Fe}$-doped sample without any template and liquid phase formers, $10 \mathrm{Fe} 0 \mathrm{LP}, 10 \mathrm{Fe} 1 \mathrm{LP}$ and $10 \mathrm{Fe} 5 \mathrm{LP}$ samples, respectively. The highest texture fraction revealed by Lotgering factor calculations was ca. 0.33 for $10 \mathrm{Fe} 1 \mathrm{LP}$ system. The texture degree of these Fe-doped $\mathrm{Al}_{2} \mathrm{O}_{3}$ ceramics could be improved by controlling the orientation of platelet particles in the matrix powder, liquid phase content, platelets amount, rheology of tape casting slurry, sintering temperature and time. However, the texture level obtained in this study was sufficient to investigate how a textured ceramic substrate could affect CNTs growth by CCVD.

\subsection{Carbon nanotubes growth over textured Fe-doped $\mathrm{Al}_{2} \mathrm{O}_{3}$}

Fig. 5 shows the schematic representation of texture development in $\mathrm{Fe}$-doped $\mathrm{Al}_{2} \mathrm{O}_{3}$ by TGG and the proposed CNTs growth over this textured ceramic substrate by CCVD. 5 vol\% $\alpha-\mathrm{Al}_{2} \mathrm{O}_{3}$ platelet shaped templates were oriented in fine Fe-doped $\mathrm{Al}_{2} \mathrm{O}_{3}$ matrix by tape casting with their basal planes parallel to the substrate surface. By a subsequent heat treatment, these templates grew at the expense of the matrix. Since they maintained their

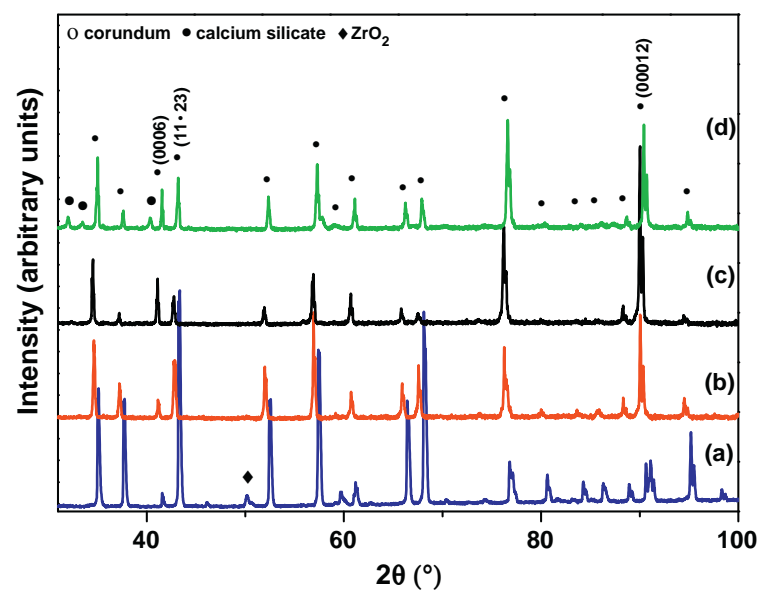

Fig. 4. XRD patterns of the (a) 10 cat.\% Fe without any platelets and LP (b) $10 \mathrm{Fe} 0 \mathrm{LP}$, (c) $10 \mathrm{Fe} 1 \mathrm{LP}$ and (d) $10 \mathrm{Fe} 5 \mathrm{LP}$ samples sintered at $1600^{\circ} \mathrm{C}$ for $2 \mathrm{~h}$. $\left(\begin{array}{lll}0 & 0 & 6\end{array}\right)$ and $(000012)$ indicate the Miller indices for basal planes of $\alpha-\mathrm{Al}_{2} \mathrm{O}_{3}$ platelets. original position during grain growth, the substrate surface was covered by the basal planes of the templates at the end of TGG process. The CNTs growth by CCVD was performed on this top basal plane oriented surface of the substrate. According to our hypothesis, when the textured substrate is subjected to CCVD, homogeneously distributed substitutional $\mathrm{Fe}^{3+}$ cations are first reduced to metallic $\mathrm{Fe}$ atoms and then coalesce into clusters and later catalytic nanoparticles by selective reduction. We now investigate the CNTs growth by CCVD over these substrates.

Fig. 6 shows the SEM micrographs of the top surface of CCVD-subjected 10Fe1LP and 10Fe5LP samples, which show

I.

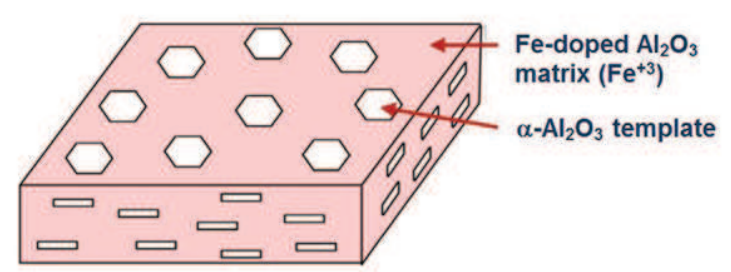

II.

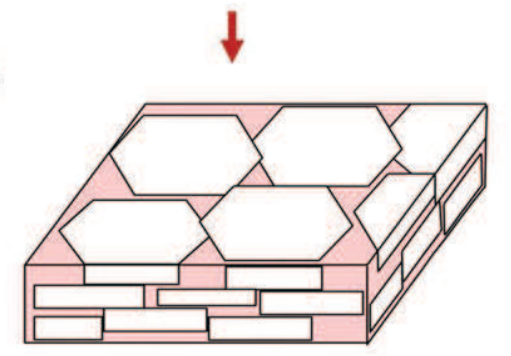

III.

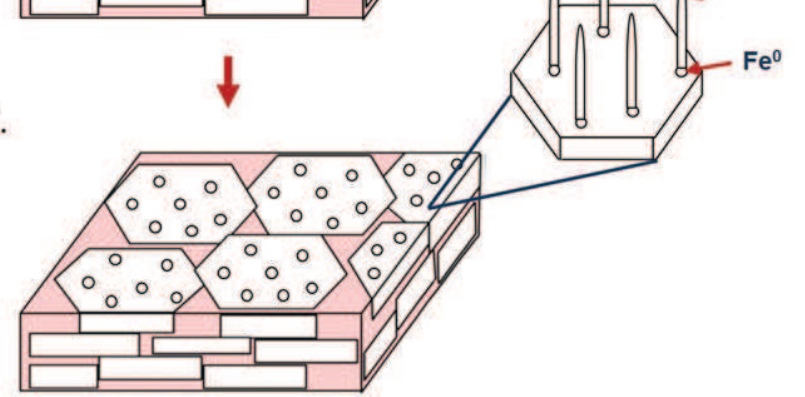

Fig. 5. Schematic representation of textured Fe-doped $\mathrm{Al}_{2} \mathrm{O}_{3}$ production by TGG method and CNTs growth over these ceramics by CCVD (I. Tape casting, II. Sintering, and III. CCVD steps). 

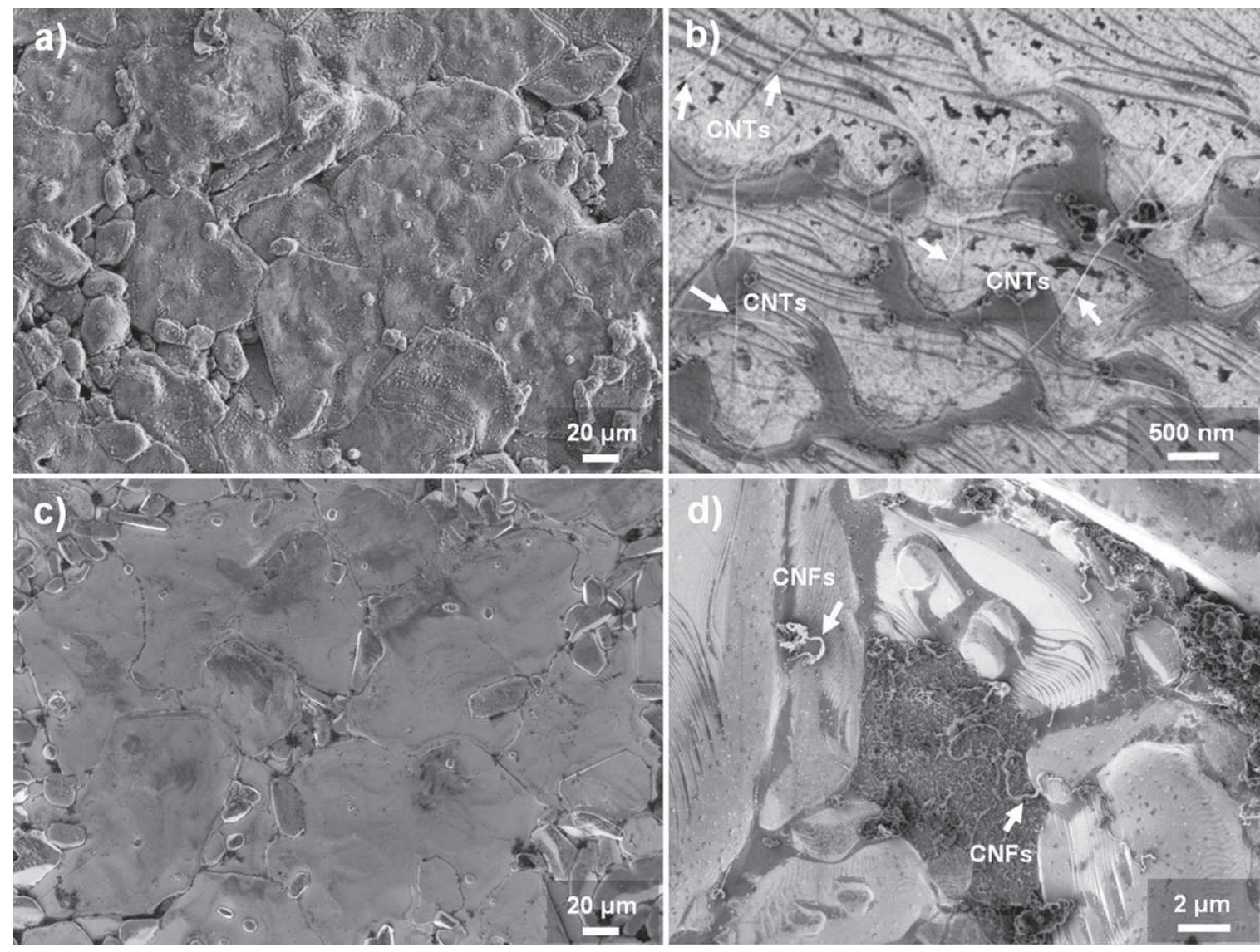

Fig. 6. SEM micrographs of 10Fe1LP (a, b) and 10Fe5LP (c, d) after CCVD process. (b) and (d) are higher magnification images of the corresponding samples. White arrows indicate carbon nanotubes (CNTs) and carbon nanofibers (CNFs) in (b) and (d), respectively.

a relatively higher degree of texture compared to others. On the contrary of our hypothesis, these substrates led to small amounts of randomly oriented CNTs. Fig. 6(a) and (b) show a general view of the surface morphology of 10Fe1LP sample after CCVD and a higher magnification image of this sample, showing both long and flexible interconnected filaments, characteristic of bundles of few-wall CNTs (indicated by white arrows) and the absence of any carbon nanofibre, respectively. This sample presented a bimodal microstructure with relatively small matrix grains and much larger template grains which were grown by consuming the matrix grains forming a quite rough surface topography (Fig. 6(a)). This surface roughness could be responsible for the small amount of randomly oriented CNTs growth since it may have affected the density and size of the catalytic nanoparticles (Fig. 6(b)). Suvaci et al., ${ }^{2,3}$ observed randomly oriented CNTs bundles over polycrystalline $\mathrm{Fe}$-doped $\mathrm{Al}_{2} \mathrm{O}_{3}$ ceramics. The authors reported that the CNTs yield was relatively low with respect to the total number of catalytic nanoparticles and they suggested that the variation in catalytic nanoparticle size on polycrystalline substrates may arise from the variation of cluster formation kinetics depending on the surface morphology and crystallographic orientation of the grains. ${ }^{2,3}$ Cao et al. ${ }^{27}$ reported dense, randomly oriented bamboo-like multi walled CNTs with different outer diameters over metallic film-coated rough polycrystalline $\mathrm{Al}_{2} \mathrm{O}_{3}$, where catalytic nanoparticles with varying sizes and shapes were formed since each nanoparticle was formed on its unique position. The surface of 10Fe5LP looked much smoother than that of 10Fe1LP, although it could be still defined as rough (Fig. 6(c)). This is most probably due to an increased liquid phase amount which promoted the growth of more faceted template grains. Very few CNTs were formed on this substrate, while a relatively higher amount of carbon nanofibers and other nontubular carbonaceous species were observed, especially on the phase which comes from the liquid phase and located at grain boundaries (Fig. 6(d)). It should be noted here that some nontubular carbon forms like carbon nanofibers were also observed even in the samples without any liquid phase former addition. This may have arised from the impurities (like $\mathrm{SiO}_{2}$ ) in the platelets which could have formed a liquid phase during sintering. Another reason could be the secondary phase segregated at grain boundaries. Probably, a high amount of $\mathrm{Fe}$ species in the grain boundary phase could have caused larger Fe nanoparticles upon reduction and thus carbon nanofibers instead of CNTs.

Although oriented CNTs could not be grown over well textured substrates, some interesting results were observed during this study. Fig. 7 shows the FEG-SEM micrographs of a 5 cat.\% Fe-doped $\mathrm{Al}_{2} \mathrm{O}_{3}$ sample, containing 5 vol\% liquid phase formers $\left(\mathrm{CaO}\right.$ and $\left.\mathrm{SiO}_{2}\right)$ and 5 vol\% $20 \mu \mathrm{m} \alpha-\mathrm{Al}_{2} \mathrm{O}_{3}$ platelets, 

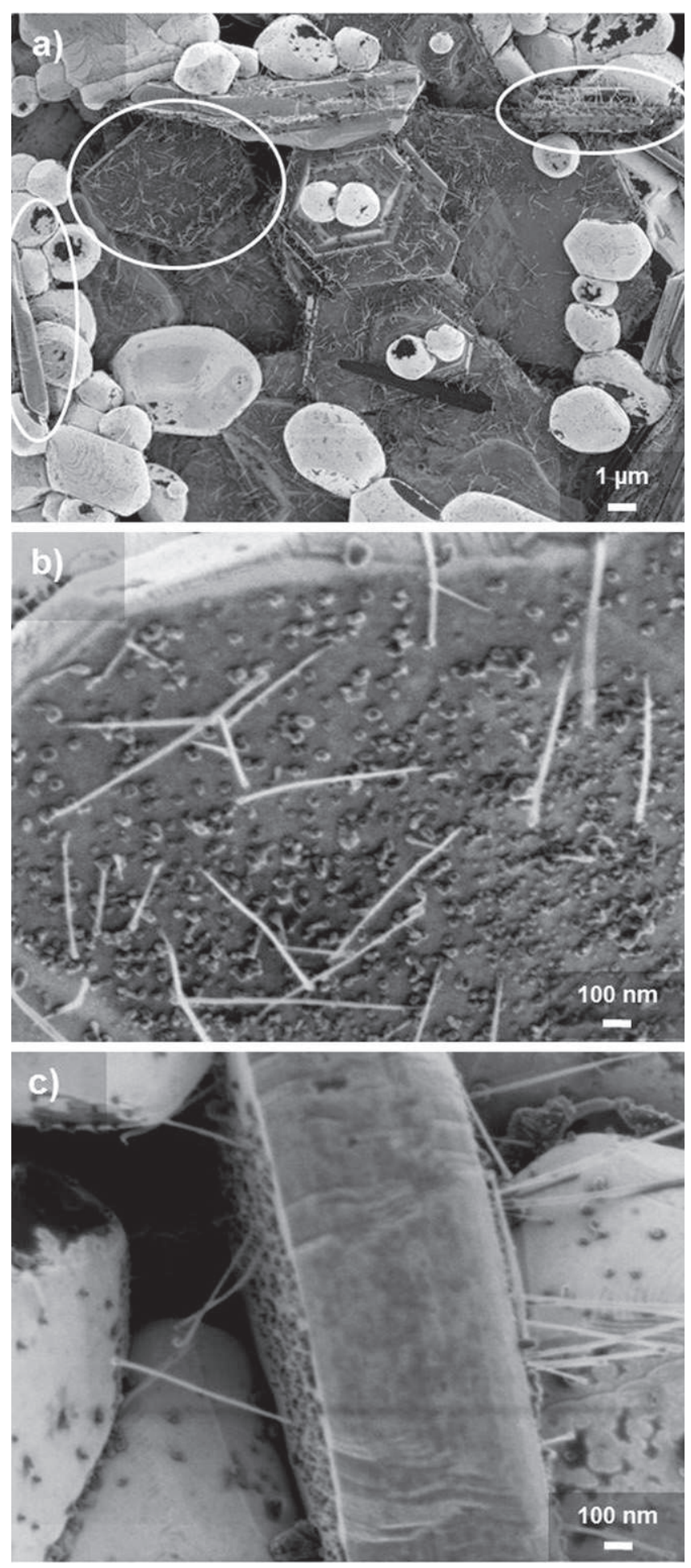

Fig. 7. (a) FEG-SEM micrograph of the vertically aligned CNT growth over basal planes of $\alpha-\mathrm{Al}_{2} \mathrm{O}_{3}$ platelets in 5 cat.\% Fe-doped $\mathrm{Al}_{2} \mathrm{O}_{3}$ sample with $5 \mathrm{vol} \%$ liquid phase former content sintered at $1400^{\circ} \mathrm{C}$ for $2 \mathrm{~h}$. (b, c) Higher magnification images of CNTs over $\alpha-\mathrm{Al}_{2} \mathrm{O}_{3}$ platelets.

after CCVD. The sample was sintered at a lower temperature $\left(1400{ }^{\circ} \mathrm{C}\right.$ ) for $2 \mathrm{~h}$. The SEM micrograph in Fig. 7(a) reveals that $\alpha-\mathrm{Al}_{2} \mathrm{O}_{3}$ platelets were distributed randomly and inhomogeneously in the matrix and they could not grow during sintering, while matrix grains grew to some extent. However, interestingly, short and very rigid CNTs were grown perpendicularly to the basal planes of these $\alpha-\mathrm{Al}_{2} \mathrm{O}_{3}$ platelets, as shown in Fig. 7(b) and (c). These are probably large diameter individual multiwall CNTs (MWNTs) rather than bundles of few-wall CNTs. It was also observed that a high amount of Fe nanoparticles, only a small part of which catalyzed CNTs growth, were formed over the basal planes of the platelets. It is proposed that some $\mathrm{Fe}^{3+}$ cations diffused into the platelets during sintering and were reduced into the $\mathrm{Fe}^{0}$ during CCVD preferentially at the basal planes of the platelets. Hongo et al. ${ }^{4}$ reported that SWNTs yield depended on the crystallographic orientation of sapphire substrate coated with Fe-film and on the film thickness. The authors explained this result with different diffusion constants of Fe on the sapphire surfaces or affinity between $\mathrm{Fe}$ and the substrate surface. ${ }^{4}$ In contrast to the textured substrates, the surface of the $\alpha-\mathrm{Al}_{2} \mathrm{O}_{3}$ platelets is quite smooth. This obviously supports the fact that the surface roughness of the substrate and crystallographic orientation of grains play a critical role on the size, location and orientation of catalytic nanoparticles and subsequently on orientation of CNTs.

These results indicated that three kinds of carbon filaments (few-wall CNTs bundles, individual MWNTs and CNFs) were grown over $\mathrm{Fe}$-doped $\mathrm{Al}_{2} \mathrm{O}_{3}$ substrates with varying degrees of texture. While rough textured substrate surface resulted in randomly oriented long and flexible CNTs bundles, perpendicularly oriented individual MWNTs were observed over relatively smooth single crystal $\alpha-\mathrm{Al}_{2} \mathrm{O}_{3}$ platelet surfaces (basal planes) in a non-textured Fe-doped $\mathrm{Al}_{2} \mathrm{O}_{3}$ sample. CNFs and other forms of non-tubular carbonaceous forms were observed at grain boundaries where segregated secondary phase and the liquid phase located and affected the catalytic Fe nanoparticle size.

\section{Conclusions}

Fe-doped $\mathrm{Al}_{2} \mathrm{O}_{3}$ ceramics with a textured microstructure were produced by templated grain growth method. Fe-doping into $\mathrm{Al}_{2} \mathrm{O}_{3}$ helped sintering; however, exaggerated grain growth occurred at high amount of Fe addition (i.e., $\sim 10$ cat.\%) at $1600{ }^{\circ} \mathrm{C}$. Introducing $\mathrm{CaO}-\mathrm{SiO}_{2}$ as liquid phase formers into the system enhanced densification and liquid-phase sintering promoted anisotropic grain growth in those samples. The degree of texture increased with the $\mathrm{Fe}$ content in the presence of liquid phase. 1 vol\% liquid phase former-added $10 \mathrm{cat} \% \mathrm{Fe}$ doped $\mathrm{Al}_{2} \mathrm{O}_{3}$ sample showed the highest degree of texture, while a very limited template growth occurred in 1 and 2 cat.\% Fe-doped samples. The Fe-doped $\mathrm{Al}_{2} \mathrm{O}_{3}$ ceramics with varying degrees of texture were subjected to CCVD and three kinds of carbon filaments (few-wall CNTs bundles, individual MWNTs and CNFs) were grown over these substrates depending on the surface roughness, the size of the catalyst nanoparticles and the grain boundary phase. Well textured substrates led to randomly oriented few amount of CNTs bundles. However, on a substrate where no template growth occurred due to random and inhomogeneous distribution of $\alpha-\mathrm{Al}_{2} \mathrm{O}_{3}$ platelets in the $\mathrm{Fe}$-doped $\mathrm{Al}_{2} \mathrm{O}_{3}$ matrix and insufficient sintering temperature, individual MWNTs were grown 
perpendicular to the basal planes of single crystal $\alpha-\mathrm{Al}_{2} \mathrm{O}_{3}$ platelets.

\section{Acknowledgements}

The financial support for this study by The Scientific and Technological Research Council of Turkey (TUBITAK) and Centre National de la Recherche Scientifique (CNRS) under the contract number 106M543 is gratefully acknowledged. One of the authors, E. Suvaci, thanks to Turkish Academy of Sciences (TUBA) for financial support through Outstanding Young Investigator Award (GEBIP) Programme. Anadolu University Scientific Research Projects Commission (under the project number of 050262) is also gratefully acknowledged for their support to this study.

\section{References}

1. Peigney A, Laurent Ch, Dobigeon F, Rousset A. Carbon nanotubes grown in-situ by a novel catalytic method. J Mater Res 1997;12:613-5.

2. Suvacı E, Çelik Y, Weibel A, Peigney A, Flahaut E. Organized growth of carbon nanotubes on Fe-doped alumina ceramic substrates. Carbon 2012;50:3092-5.

3. Bozkaya Y. Karbon Nanotüp Sentezinde Kullanılmak Üzere Fe-Katkılı $\mathrm{Al}_{2} \mathrm{O}_{3}$ Seramik Tozlarının ve Altlıkların Üretimi. M.Sc. Thesis. Turkey: Anadolu University; 2008.

4. Hongo H, Yudasaka M, Ichihashi T, Nihey F, Iijima S. Chemical vapor deposition of single-wall carbon nanotubes on iron-film-coated sapphire substrates. Chem Phys Lett 2002;361:349-54.

5. Ago H, Nakamura K, Ikeda K, Uehara N, Ishigami N, Tsuji M. Aligned growth of isolated single-walled carbon nanotubes programmed by atomic arrangement of substrate surface. Chem Phys Lett 2005;408:433-8.

6. Han S, Liu X, Zhou CJ. Template-free directional growth of singlewalled carbon nanotubes on a- and r-plane sapphire. Am Chem Soc 2005; 127(15):5294-5.

7. Ismach A, Segev L, Wachtel E, Joselevich E. Atomic-step-templated formation of single wall carbon nanotube patterns. Angew Chem Int Ed 2004;43(45):6140-3

8. Kimura T, Yahimoto T, Iida N, Fujita Y, Yamaguchi T. Mechanism of grain orientation during hot-pressing of bismuth titanate. J Am Ceram Soc 1989;72:85-9.

9. Ma Y, Bowman KJ. Texture in hot-pressed or forged alumina. J Am Ceram Soc 1991;74:2941-4.

10. Watanabe H, Kimura T, Yamaguchi T. Sintering of platelike bismuth titanate powder compacts with preferred orientation. J Am Ceram Soc 1991;74:139-47.
11. Seabaugh MM, Hong SH, Messing GL. Processing of textured ceramics by templated grain growth. In: Tomsia AP, Glaeser A, editors. Ceramic microstructure: control at the atomic level. New York: Plenum; 1998. p. 303-10.

12. Cordier A, Peigney A, De Grave E, Flahaut E, Laurent C. Synthesis of the metastable $\alpha-\mathrm{A}_{11.8} \mathrm{Fe}_{0.2} \mathrm{O}_{3}$ solid solution from precursors prepared by combustion. J Eur Ceram Soc 2006;26:3099-111.

13. Lotgering FK. Topotactical reactions with ferrimagnetic oxides having hexagonal crystal structures-I. J Inorg Nucl Chem 1959;9: 113-23.

14. Flahaut E, Bacsa R, Peigney A, Laurent Ch. Gram-scale CCVD synthesis of double walled carbon nanotubes. Chem Commun 2003;12: 1442-3.

15. Ozer IO, Karademir B, Dogan A, Suvaci E, Missiaen JM, Bouvard D, et al. Anisotropic shrinkage in solid state sintering of alumina ceramics with oriented platelets. J Am Ceram Soc 2006;89:1972-6.

16. Belmonte M, Moreno R, Moya JS, Miranzo P. Obtention of highly dispersed platelet reinforced $\mathrm{Al}_{2} \mathrm{O}_{3}$ composites. J Mater Sci 1994;29: 179-83.

17. Carisey T, Laugier-Werth A, Brandon DG. Control of texture in $\mathrm{Al}_{2} \mathrm{O}_{3}$ by gel-casting. J Eur Ceram Soc 1995;15:1-8.

18. Rao WR, Cutler IB. Effect of iron oxide on the sintering kinetics of $\mathrm{Al}_{2} \mathrm{O}_{3}$. J Am Ceram Soc 1973;56:588-93.

19. Tartaj J, Messing GL. Anisotropic grain growth in $\alpha-\mathrm{Fe}_{2} \mathrm{O}_{3}$-doped alumina. J Eur Ceram Soc 1997; 17:719-25.

20. Ikuma Y, Gordon RS. Effect of doping simultaneously with iron and titanium on the diffusional creep of polycrystalline alumina. J Am Ceram Soc 1983;66:139-47.

21. Muan A. On the stability of the phase $\mathrm{Fe}_{2} \mathrm{O}_{3}-\mathrm{Al}_{2} \mathrm{O}_{3}$. Am $J$ Sci 1958;256:413-22.

22. Tartaj P, Tartaj J. Microstructural evolution of iron-oxide-doped alumina nanoparticles synthesized from microemulsions. Chem Mater 2002; 14:536-41.

23. Seabaugh MM. Texture development in liquid phase sintered alpha alumina via anisotropic template growth. Ph.D. Dissertation. University Park: The Pennsylvania State University; 1998.

24. Seabaugh MM, Messing GL, Brahmaroutu B. Anisotropic template growth in textured alumina. In: You HI, Joong S, editors. Interfaces '98. London: Institute of Materials; 2000

25. Suvaci E, Seabaugh MM, Messing GL. Reaction-based processing of textured alumina by templated grain growth. J Eur Ceram Soc 1999;19:2465-74.

26. Seabaugh MM, Kerscht I, Messing GL. Texture development by templated grain growth in liquid-phase sintered alpha-alumina. J Am Ceram Soc 1997;80:1181-8.

27. Cao PJ, Zhu DL, Liu WJ, Ma XC. The effect of substrate morphology on the diameter distribution of carbon nanotubes grown on silica and ceramic substrates. Mater Lett 2007;61(8-9):1899-903. 